\title{
Carboximetilação de Polpas de Bagaço de Cana-de-Açúcar e Caracterização dos Materiais Absorventes Obtidos
}

\author{
Luís C. Morais e Sérgio P. Campana Filho
}

Resumo: Os processos soda/antraquinona e etanol/água foram aplicados à produção de polpas de fibras e de medulas de bagaço de cana-de-açúcar. Tais polpas foram carboximetiladas em suspensão de isopropanol/água $(8 / 1 \mathrm{~m} / \mathrm{m})$ por 4 horas a $80^{\circ} \mathrm{C}$, empregando a relação molar $8,5 / 5,4 / 1$ para ácido monocloroacético/hidróxido de sódio/celulose. Os graus médios de susbtituição dos produtos carboximetilados foram determinados por espectroscopia ${ }^{1} \mathrm{H}$ R.M.N. e variaram entre 0,44 e $1,27 \mathrm{em}$ função da polpa empregada na derivatização. Os derivados mais substituídos foram os melhores absorventes, sugerindo que a capacidade de retenção de água desses produtos está diretamente associada a seus graus de substituição.

Palavras-chave: Bagaço de cana-de-açúcar, polpação etanol/água, polpação soda/antraquinona, absorvente, carboximetilcelulose.

\section{Introdução}

A utilização da biomassa vegetal como fonte de matéria-prima para a produção de novos materiais vem despertando grande interesse devido a sua abundância e pelo fato de existirem muitas reservas renováveis ${ }^{[1]}$. Outras vantagens do uso das fibras naturais presentes na biomassa estão associadas à sua biodegradabilidade e à redução de densidade dos materiais produzidos a partir delas. A mais abundante das macromoléculas constituintes da fibra vegetal, a celulose, é um biopolímero hidrofílico, o que geralmente exige que modificações sejam introduzidas em sua estrutura para torná-lo compatível com os materiais sintéticos e para que possa ser mais facilmente processada ${ }^{[2]}$.
Entretanto, essa característica das fibras vegetais, a de possuir afinidade por água, também pode ser aproveitada, por exemplo, na produção de materiais absorventes de água ${ }^{[3-5]}$. Esses materiais apresentam um grande potencial de aplicação já que os absorventes ocupam um lugar de destaque no mercado mundial e são intensivamente consumidos nas sociedades japonesa, norte-americana e européia ${ }^{[6]}$ como produtos de higiene pessoal (guardanapos, fraldas, toalhas), espessantes de produtos alimentícios (como carboximetilcelulose, xantana, gelana, pectinas, etc) e como umidificadores de solo usados na agricultura ${ }^{[7,8]}$. Em países como o Brasil, que produz grandes volumes de açúcar e álcool através do processamento de canade-açúcar, são disponíveis grandes quantidades do 
bagaço gerado dessa atividade e seu aproveitamento para diversos fins vem sendo constantemente estudado $^{[2,9-16]}$. Neste trabalho polpas de bagaço de cana-de-açúcar são preparadas pelos processos etanol/água e soda/antraquinona e suas capacidades de absorver água comparadas com as de derivados obtidos após sua modificação através da realização de reação de carboximetilação. No sentido de melhorar a capacidade absorvente das polpas, sem entretanto torná-las hidrossolúveis, a reação de carboximetilação é realizada em condições que resultem na obtenção do derivado sob a forma ácida, visto que a forma sódica é completamente solúvel em água mesmo para baixos graus de substituição ${ }^{[17]}$.

\section{Experimental}

\section{Obtenção e caracterização de polpas ${ }^{[18,19]}$}

As matérias-primas empregadas neste trabalho são fibras e medula do bagaço de cana-deaçúcar, separadas por processo de peneiramento. As fracões separadas de fibras e de medula foram então suspensas em água a $160^{\circ} \mathrm{C}$ durante $30 \mathrm{~min}$. O material obtido, contendo um teor reduzido de polioses, foi submetido às polpações soda/antraquinona (soda/AQ) e etanol/água (etanol $/ \mathrm{H}_{2} \mathrm{O}$ ).

$\mathrm{Na}$ polpação soda/AQ foi empregada a relação $12: 1(\mathrm{~m} / \mathrm{m})$ de licor/amostra, sendo o licor constituído de $16 \%$ de álcali ativo $\left(\mathrm{Na}_{2} \mathrm{O}\right)$ e $0,15 \%$ antraquinona (AQ). A temperatura do reator contendo licor e amostra foi elevada para $160^{\circ} \mathrm{C}$ e, alcançada esta temperatura, a reação prosseguiu por $60 \mathrm{~min}$.

$\mathrm{Na}$ polpação etanol/água foram empregadas relações licor/amostra de $30: 1(\mathrm{~m} / \mathrm{m})$ para a medula e de $1: 11(\mathrm{~m} / \mathrm{m})$ para as fibras, sendo o licor composto por mistura etanol/água $(1: 1 \mathrm{~m} / \mathrm{m})$. A temperatura do reator contendo licor e amostra foi elevada para $190^{\circ} \mathrm{C}$ e, alcançada esta temperatura, a reação prosseguiu por $60 \mathrm{~min}$.

As polpas obtidas foram branqueadas empregando proporção água/polpa bruta de $40 / 1(\mathrm{~m} / \mathrm{m})$. A suspensão foi termostatizada a $70 \pm 2^{\circ} \mathrm{C}$, foram adicionados $6,0 \mathrm{~mL}$ de ácido acético glacial e 15,0 $\mathrm{g}$ de clorito de sódio e a reação prosseguiu por 60 $\min$.
As polpas branqueadas foram caracterizadas segundo as normas Tappi, sendo determinados os teores de celulose, $\alpha$-celulose, número microkappa, cinzas e umidade. Graus de polimerização e índices de cristalinidade das polpas foram determinados por viscosimetria ${ }^{[20]}$ e difração de raios$\mathrm{X}^{[10]}$, respectivamente.

\section{Obtenção e caracterização de} carboximetilcelulose e $^{[11,12,18]}$

Em reator de vidro foram misturados $8,5 \mathrm{~g}$ de polpa e mistura isopropanol/água, imprimindo-se agitação mecânica vigorosa até obter boa dispersão. Em seguida foi adicionada uma solução aquosa de $\mathrm{NaOH}$ para resultar em relação $\mathrm{NaOH} /$ celulose de 5,4:1 [mol/mol]. Após 30min à temperatura ambiente, solução aquosa de ácido monocloroacético (AMA) foi adicionada à suspensão resultando em relação AMA/celulose de 8,8:1 [mol $/ \mathrm{mol}]$. A temperatura do reator foi elevada para $80{ }^{\circ} \mathrm{C}$ e a reação prosseguiu por $4 \mathrm{~h}$. A suspensão foi filtrada e o produto carboximetilado foi lavado com misturas metanol/água e seco a temperatura ambiente. Os derivados carboximetilados foram caracterizados quanto ao grau médio de substituição por espectroscopia de ressonância magnética nuclear de próton $\left({ }^{1} \mathrm{H} \text { R.M.N. }\right)^{[21]}$.

As polpas carboximetiladas foram armazenadas em dessecadores contendo agente secante $\left(\mathrm{P}_{2} \mathrm{O}_{5}\right)$ ou soluções saturadas de diferentes substâncias, de modo a constituirem ambientes de diferentes umidades relativas (UR) no intervalo $0 \%$ - $100 \%{ }^{[18,22]}$. As amostras foram condicionadas nesses ambientes durante 18 dias e então submetidas a análises térmicas. A capacidade de reter água foi determinada como a perda de massa, determinada por análises termogravimétricas (TGA) em equipamento Shimadzu TG-50, sob fluxo de ar sintético $(10 \mathrm{~mL} / \mathrm{min})$ e razão de aquecimento de $10^{\circ} \mathrm{C} / \mathrm{min}$, no intervalo $\left[25^{\circ} \mathrm{C}, 200^{\circ} \mathrm{C}\right]$. As amostras também foram analisadas por calorimetria exploratória diferencial em equipamento Shimadzu (DSC-50) por aquecimento à taxa de $1{ }^{\circ} \mathrm{C} / \mathrm{min}$, no intervalo $\left[-60^{\circ} \mathrm{C}, 25^{\circ} \mathrm{C}\right]$. Essas análises permitem determinar a variação do ponto de fusão da água em função da ocorrência e da importância de interações com a rede polimérica do absorvente, empregando as curvas da água pura como referência ${ }^{[23]}$. 
Tabela 1. Características das polpas branqueadas de fibras e de medulas:

\begin{tabular}{lcccc}
\hline \multicolumn{1}{c}{$\mathbf{X}$} & PMSbr & PFSbr & PMEbr & PFEbr \\
\hline Rendimento $(\%)^{(\mathrm{a})}$ & 21 & 28 & 35 & 37 \\
Celulose $(\%)^{(\mathrm{b})}$ & $95,32 \pm 0,75$ & $95,69 \pm 0,68$ & $90,20 \pm 1,17$ & $93,97 \pm 1,00$ \\
$\alpha$-celulose $(\%)^{(\mathrm{c})}$ & $89,39 \pm 1,68$ & $92,33 \pm 1,57$ & $86,43 \pm 1,85$ & $87,84 \pm 1,23$ \\
Número microkappa & 0,60 & 0,51 & 2,00 & 1,00 \\
Cinzas $(\%)$ & $0,97 \pm 0,28$ & $0,28 \pm 0,13$ & $1,53 \pm 0,12$ & $0,51 \pm 0,16$ \\
Umidade $(\%)$ & $9,76 \pm 0,31$ & $10,00 \pm 0,12$ & $9,61 \pm 0,23$ & $9,73 \pm 0,40$ \\
\hline
\end{tabular}

(a) relativo à matéria-prima bruta e isenta de umidade;

(b) e (c) relativos à massa de holocelulose isenta de umidade.

PMSbr: polpa de medula soda/AQ; PMEbr: polpa medula etanol/água; PFSbr: polpa de fibra soda/AQ; PFEbr: polpa de fibra etanol/água.

\section{Resultados e Discussão}

Visando a obtenção de matérias-primas com alto teor de celulose, foram realizados o pré-tratamento de fibras e medula e o branqueamento das polpas brutas obtidas pelos diferentes processos de deslignificação. Na pré-hidrólise foram eliminados $73 \%$ e $58 \%$ das polioses de medula e fibras, respectivamente ${ }^{[18]}$. O branqueamento, um tratamento oxidativo visando a remoção das substâncias cromóforas, principalmente ligninas, também foi eficiente pois os valores de número microkappa (Tabela 1) equivalem a teores em torno de $0,10 \%$ e $0,30 \%$ de lignina residual nas polpas branqueadas soda/AQ e etanol/água, respectivamente. Os rendimentos até a obtenção das polpas branqueadas a partir das matérias-primas mostram que houve uma considerável perda de celulose ao longo das etapas executadas, mas os teores de a-celulose são elevados $(>85 \%)$ e tais polpas são classificadas como polpas para dissolução ${ }^{[19]}$. Os graus médios de polimerização e os índices de cristalinidade também foram determinados (Tabela 2), o que permite avaliar o efeito das etapas executadas sobre a qualidade das polpas obtidas.

Como pode ser contastado (Tabela 2), a polpação soda/antraquinona levou à obtenção das polpas menos degradadas, independentemente da

Tabela 2. Graus médios de polimerização $(\overline{\mathrm{GP}})$ e índices de cristalinidade $\left(\mathrm{I}_{\mathrm{CR}}\right)$ das polpas.

\begin{tabular}{lcccc}
\hline & PMS & PFS & PME & PFE \\
\hline $\begin{array}{l}\text { Grau de polimerização } \\
\text { das polpas brutas }\end{array}$ & 597 & 719 & 443 & 299 \\
$\begin{array}{l}\text { Grau de polimerização } \\
\text { polpas branqueadas }\end{array}$ & 406 & 508 & 192 & 285 \\
\begin{tabular}{l}
$\mathrm{I}_{\mathrm{CR}}(\%)$ \\
\hline
\end{tabular} & 60 & 59 & 52 & 68 \\
\hline
\end{tabular}

matéria-prima considerada, conforme relatado na literatura $^{[19]}$. O branqueamento resultou em degradação adicional, como pode ser avaliado pela diminuição do grau médio de polimerização, que foi mais importante para as polpas de medula e acompanhada de significativa perda de cristalinidade quando foi mais acentuada. Apesar das diferenças citadas, as polpas apresentaram reatividade semelhante pois os graus médios de substituição dos produtos carboximetilados são próximos, embora os obtidos a partir de polpas de fibras apresentem valores $20 \%$ maiores (Tabela 3 ).

Tabela 3. Graus médios de substituição das polpas carboximetiladas.

\begin{tabular}{cc}
\hline Amostras & $\overline{\mathbf{G S}}$ \\
\hline CMCMS & 1,06 \\
CMCME & 0,96 \\
CMCFS & 1,21 \\
CMCFE & 1,27 \\
\hline
\end{tabular}

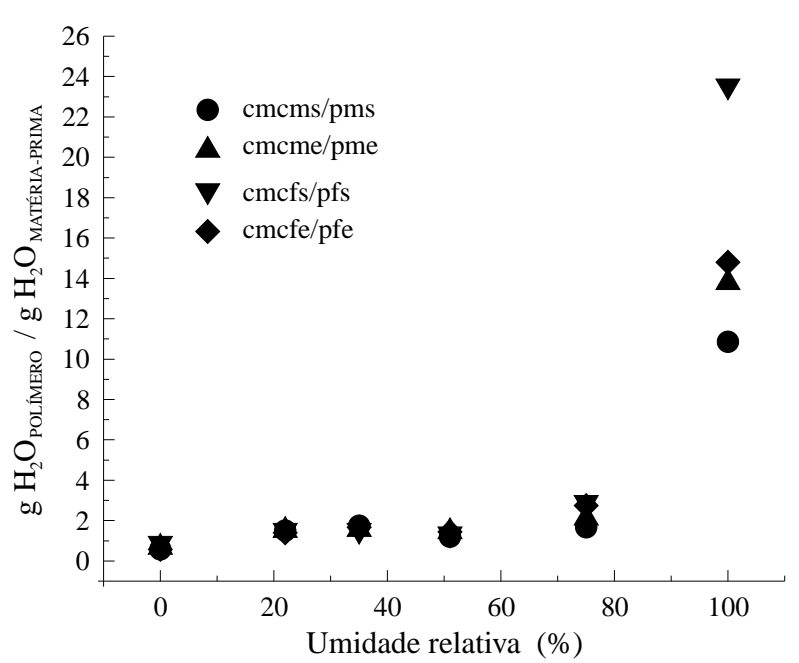

Figura 1. Relação entre as massas de água absorvidas pelas polpas carboximetiladas e pela matéria-prima de partida, em ambientes de diferentes umidade relativa. 
Todas as polpas carboximetiladas são mais absorventes que as polpas de partida o que, a princípio, pode ser atribuído ao maior número de sítios iônicos (grupos carboximetila na forma ) e à capacidade de expansão da rede macromolecular, porém as diferenças entre os produtos carboximetilados só são evidenciadas quando armazenados em ambiente saturado de umidade (Figura 1).

Nesse ambiente é observado que as amostras mais substituídas são as mais absorventes, demonstrando a influência do conteúdo de grupos iônicos sobre a capacidade absorvente das polpas carboximetiladas. De fato, a presença de grupos carboximetila, que são muito mais ionizáveis que as hidroxilas da celulose, resulta em interações solvente/rede mais favoráveis o que, somado à repulsão eletrostática entre os sítios ionizados distribuídos ao longo das cadeias, provoca a expansão da rede macromolecular. Entretanto, este não é o único fator importante e nem sempre é possível determinar os fatores que contribuem para a capacidade absorvente ${ }^{[24]}$. De fato, as polpas carboximetiladas de fibras possuem valores de graus médios de substituição praticamente idênticos, mas a amostra obtida a partir da polpa soda/ antraquinona, amostra CMCFS, apresenta capacidade de absorção de água superior ao da amostra CMCFE, preparada a partir de polpa etanol/água. Nesse caso pode ser inferido que, por terem sido preparadas a partir de matérias-primas cujos graus médios de polimerização diferem por um fator 1,8 (Tabela 2), as amostras diferem quanto à capacidade de expansão de suas redes para abrigar água em excesso devido a essa característica. Por outro lado, a capacidade de expansão da rede polimérica também é função da mobilidade dos segmentos poliméricos, o que está relacionado à morfologia e ao grau de ordenamento da amostra. As amostras CMCMS e CMCME possuem conteúdos de grupos iônicos semelhantes e, embora a polpa empregada na obtenção da primeira amostra possua grau médio de polimerização duas vezes maior, é a segunda amostra que apresenta maior capacidade de absorver água. Tal comportamento não deve, entretanto, ser atribuído às pequenas diferenças de cristalinidade das polpas empregadas e, provavelmente, está associado a diferentes distribuições de grupos iônicos e de domínios cristalinos.

Devido às interações com a rede polimérica, as moléculas de água absorvidas nesses sistemas apre- sentam propriedades diferentes, sendo classificadas de água parcialmente livre, ou congelável, e água ligada, ou não-congelável, como resultado de interações relativamente fortes e muito fortes, respectivamente ${ }^{[23]}$. Assim, os pontos de fusão da água pura, tomada como referência, e da água congelável absorvida em amostras de absorventes estudados neste trabalho são diferentes (Figura 2A). Entretanto, a intensidade das interações e também a importância do deslocamento do ponto de fusão da água, dependem da natureza do sistema e do teor de água disponível (Figura 2B). Assim, os pontos de fusão das moléculas de água absorvidas na amostra CMCFS são $-1,26^{\circ} \mathrm{C}$ (Figura $2 \mathrm{~A}$ ) e $-13^{\circ} \mathrm{C}$ (Figura 2B) para teores de umidade relativa $100 \%$ e $75 \%$, respectivamente. Também, na polpa carboximetilada as interações entre moléculas de água e rede polimérica são mais fortes e o deslocamento do ponto de fusão mais importante que o observado na polpa de partida (Figura 2B), como resultado
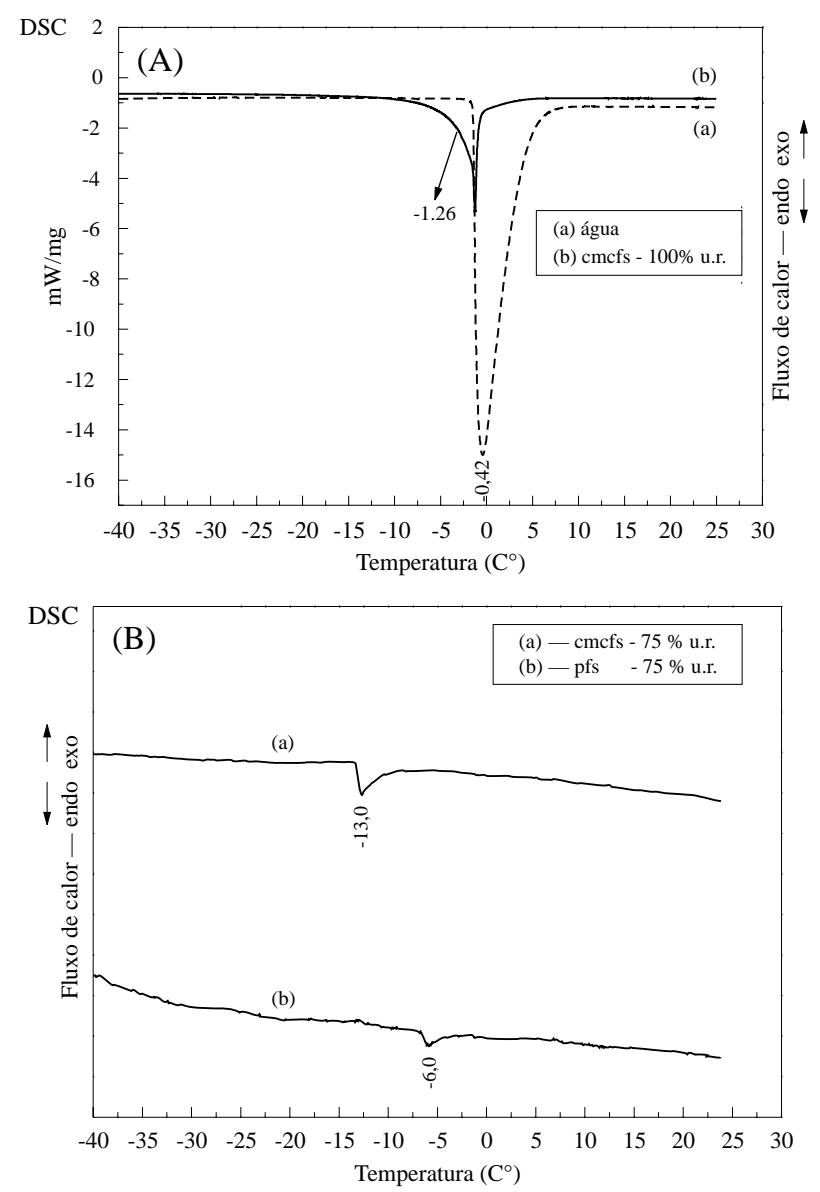

Figura 2. Curvas DSC da água pura e da amostra CMCFS em ambiente saturado de umidade (A) e da polpa PFS e do correspeondente derivado carboximetilado, amostra CMCFS, em ambiente com umidade relativa $75 \%$ (B). 
da maior hidrofilicidade dos grupos carboximetila. Em função de suas características e do teor de umidade do ambiente em que foram condicionadas, as polpas carboximetiladas deste trabalho apresentaram temperaturas de fusão da água congelável no intervalo $\left[-13^{\circ} \mathrm{C},-4,5^{\circ} \mathrm{C}\right]^{[18]}$.

\section{Conclusão}

Os métodos de polpação empregados resultaram em polpas de muito boa qualidade, que podem ser classificadas como polpas químicas, conforme avaliado pelos teores de $\alpha$-celulose, sendo adequadas à preparação de carboximetilcelulose e outros derivados. A polpação soda/ AQ levou à obtenção de polpas contendo celulose menos degradada, o que foi constatado pelos maiores valores de graus de polimerização, e todas as polpas branqueadas apresentaram índices de cristalinidade próximos (50-60\%), como avaliado por difração de raios-X. Os graus de substituição e de polimerização e, provavelmente, a morfologia das polpas carboximetiladas, determinam a máxima capacidade de absorção de água dos derivados obtidos. As análises térmicas desses derivados mostraram que diferentes tipos de água existem nos sistemas, os quais correspondem a diferentes graus de interação com a rede polimérica. A existência de interações fortes entre as moléculas de água e a rede polimérica se manifesta como alterações na temperatura de fusão da água, as quais dependem das características das amostras, principalmente do seu conteúdo de grupos carboximetila, e do teor de umidade do ambiente em que se encontram.

\section{Agradecimento:}

Os autores agradecem à FAPESP e ao $\mathrm{CNPq}$ pelas concessões de recursos nas formas de auxílio à pesquisa e de bolsas que viabilizaram a execução deste trabalho.

\section{Referências Bibliográficas}

1. Rowell, R.M.; Caulfield, D.F.; Chen, G.; Ellis, W.D.; Jacobson, R.E.; Lange, S.E. E
Schumann, R. - "Recent Advances in AgroFiber/Thermoplastics Composites"; in: Proceedings of Second International Symposium on Natural Polymer and Composites, p.11, Atibaia-SP, (1998).

2. Gandini, A. Polymer from Renewable Resources. In: Comprehensive Polymer Science, p.527, Oxford, Pergamon, (1992).

3. Ricard, A.; Pierre, M. Les hydrorétenteurs: du laboratoire à I'índustrie. Chemical Abstract, v.104, p.21-25, (1986).

4. Gross, J.R. The evolution of absorbent materials. In: Absorbent Polymer Technology. New York, Elsevier Science Publishers, p.3-21 (1990).

5. Esposito, F. et al. Water sorption in cellulosebased hydrogels. Journal of applied Polymer Science, v.60, p.2403-2407, (1996).

6. Japan Chemical Week, July 5, (1990).

7. Bucholz, F.L. An idea whose time has come. Journal of Chemical Education, v.73, n.6, p 513-515, (1996).

8. Engelhardt, F.; Gerlinde, E.; Rüdiger, F. Advanced Materials, v.4, p.227-231, (1992).

9. Instituto Cubano de Investigaciones de Los Derivados de La Caña de Azúcar. Colección Geplacea. $2^{\mathrm{a}}$ edicion, p.140 (1990).

10. Fengel, D.; Wegner, G. - "Wood - Chemistry, Ultrastructure, Reaction”, Walter de Gruyter \& Co., Berlim (1983).

11. Martinez, C.M.F. Obtenção e Caracterização de materiais absorventes através da carboximetilação de polpa Etanol/água de medula de bagaço de cana-de-açúcar. São Carlos, 120p. Dissertação (Mestrado) - Instituto de Física e Química de São Carlos, Universidade de São Paulo (1995).

12. Caraschi, J.C. Estudo das relações estrutu$\mathrm{ra}$ /propriedades de carboximetilcelulose obtida por dervatização de polpa de canade-açúcar. São Carlos, 188p . Tese (Doutorado) - Instituto de Física e Química de São Carlos, Universidade de São Paulo (1997). 
13. LA INDUSTRIA DE LOS DERIVADOS DE LA CAÑA DE AZÚCAR. Instituto Cubano de Investigaciones de Los Derivados de Caña de Azúcar-(ICIDCA)-Editorial Cientifico-Técnico La Havana, 2a Parte, Capítulo 4, (1990).

14. Pereira, R., Campana Filho, S.P., Curvelo, A.A.S., Gandini, A. - Cellulose, 4, p.21 (1997).

15. Joaquim, A.P. - "Estudos das etapas de ativação no processo de benzilação da polpa de medula de bagaço de cana-de-açúcar", Dissertação(Mestrado), Instituto de Química de São Carlos, Universidade de São Paulo, Brasil (1997).

16. Britto, D. - "Estudo da reação de benzilação de fibras e polpas de fibras do bagaço de cana-de-açúcar", Dissertação (Mestrado), Instituto de Química de São Carlos, Universidade de São Paulo, Brasil (1998)

17. Juste, K. E.; Majewicz, T.G. eds. Enciclopedia of Polymer Science and Engineering. New York, John Wiley \& Sons, v.3, p.201-204 (1985).

18. Morais, L.C.; Estudos sobrea preparação e caracterização de materiais absorventes a par- tir dos polissacarídeos quitina e celulose. São Carlos, 97p. Dissertação (Mestrado). Instituto de Química de São Carlos, Universidade de São Paulo (1999).

19. Carashi, J.C., Campana Filho, S.P., Curvelo, A.A.S. - Polímeros: Ciência e Tecnologia, v.jul/set, p.24 (1996).

20. SCAN-C15:62. Scandinavian Pulp, Paper and Board - Viscosity of Cellulose in Cupricethylenediamine Solution (CED), (1962).

21. Floyd, F.L.H. Proton Nuclear Magnetic Resonance Spectrometry for determination of Substituints and Their Distribution in Carboxymethylcellulose. Analytical Chemistry, v.52, p.913-916, (1980).

22. Lide, D.R.; Frederikse, H.P.R. CRC Handbook of Chemistry and Physics. 76.ed. New York, CRC Press, Section 15-23 (1996).

23. Berthold, J. et al. Types of adsorbed water in relation to the ionic groups and their counterions for some cellulose derivatives. Polymer, v.35, n.26, p.5729-5736, (1994).

24. Tanaka,T. Gels. Scientific American, v.244, p.110-125, (1981). 